\title{
Taxonomic Diversity and Taxonomic Dominance: The Example of Forest Plantations in South-Central Chile
}

\author{
Andreas Ch. Braun \\ Andreas Ch. Braun, Institute of Regional Science, IfR, Karlsruhe Institute of Technology (KIT), Karlsruhe, \\ Germany \\ Email: andreas.ch.braun@kit.edu
}

Received 1 December 2014; accepted 18 May 2015; published 21 May 2015

Copyright (C) 2015 by author and Scientific Research Publishing Inc.

This work is licensed under the Creative Commons Attribution International License (CC BY). http://creativecommons.org/licenses/by/4.0/

cc) (i) Open Access

\section{Abstract}

The study describes an analysis of the impact of plantation forestry on the taxonomic diversity of plants in south-central Chile. In this biodiversity hotspot, plantations of non-native species like Pinus radiata D. Don, Eucalyptus globules Labill. and Populus nigra L. have largely replaced native deciduous and sclerophyllous forests. The study compares taxonomic diversity of commercial plantations and native forests using taxonomic distinctness and diversity and the Simpson diversity index. Most of these indexes attest a considerably reduced taxonomic diversity to plantations. However, taxonomic distinctness values for $P$. radiata plantations seem to contradict other indexes at first glance. It is shown that the higher values of taxonomic distinctness of $P$. radiata plantations come from taxonomic dominance. Taxonomic dominance describes the fact that $P$. radiate-a member of the infradivison of Gymnospermae-bears only little taxonomic resemblance to other plants, which are Angiospermae. Thus, it strongly dominates the taxonomic distinctness index and the high taxonomic resemblance of other plant within its plots is neglected. Indexes are developed that identify such dominant species and adjust for taxonomic dominance in taxonomic diversity analyses. After this adjustment, all indexes provide a coherent image on taxonomic diversity. Plantation forestry produces a considerable decline of taxonomic diversity. Taxonomic diversity analysis provides valuable insights in biodiversity impacts and complements standard analyses.

\section{Keywords}

Taxonomic Diversity, Central Chile, Biodiversity Hotspots, Plantation Forestry, Pinus radiata 


\section{Introduction}

The coastal range of south-central Chile has experienced a rapid and intense transformation of land-use since the arrival of European colonists [1]-[5]. Land-use transformation has accelerated even more since the neoliberal turn during the Pinochet era until today. Within this period, forest plantations with commercial purposes have significantly been extended [6]-[8]. The historical roots of plantations trace back to the end of the 18th century [9] [10]. Then, first Pinus plantations have been established for soil protection purposes at sites which had been fire-cleared. However, during the neoliberal turn, plantation forestry, vigorously subsidized by the government, has extended spatially. This extension caused rapid and spacious deforestation of deciduous Nothofagus spp. Blume forests and forests of sclerophyllous species like Cryptocarya alba Looser, Peumus boldus Molina and Lithrea caustica (Molina) Hook \& Arn. [1] [12]-[14]. During the first two decades of deforestation, native forests have lost around $65 \%$ of their original area [1]. The rate and intensity of this replacement cause concern with regard to biodiversity conservation; especially since the coastal range of south-central Chile is considered one of the 25 biodiversity hotspots around the world [15]-[17]. Besides species-oriented biodiversity, one aspect of biodiversity, which complements and enhances standard biodiversity assessments, is taxonomic diversity [18]. Taxonomic diversity extends the species-oriented perspective of traditional biodiversity assessments and incorporates higher taxonomic ranks into the analysis.

Within this article, taxonomic distinctness and taxonomic diversity of plantations in south-central Chile are analyzed and compared to native forests. Plant formations like Pinus are naturally dominated by the abundance of the plantation tree which influences measures on species-oriented biodiversity like the Simpson diversity index. However, since Gymnospermae like Pinus bear an inherent taxonomic dissimilarity to other plant which mainly are Angiospermae, it can also dominate taxonomic diversity. This can lead to biased interpretations of taxonomic diversity. For this reason, measures for taxonomic dominance are introduced. Taxonomic dominance relates to the fact that single species may dominate standard indexes of taxonomic diversity. Measures on taxonomic dominance allow assessing the relative contribution of individual species to traditional measures. Furthermore, they allow converting traditional measures for taxonomic diversity into measures that take account of the dominance of individual species. The remainder of the article is organized as follows. Section 2 illustrates the main objectives of this study. Section 3 introduces to the coastal area of south-central Chile. Section 4 describes indexes of taxonomic diversity from literature which are used herein. Section 5 proposes modifications and further indexes for taxonomic diversity. Section 6 presents the results of the case study which are then discussed in Section 7 \& Section 8 concludes the article.

\section{Objectives of the Study}

The study aims to contribute both regional and theoretic aspects of biodiversity. The regional aspects concern the consequences of landscape transformation in south-central Chile. Numeric figures are provided, which compare the taxonomic biodiversity in commercial forestry plantations to the native forests that are replaced by these plantations.

Concerning the theory of biodiversity research, the study proposes additional measures for taxonomic distinctness. These measures can be used to assess the degree to which individual species dominate taxonomic distinctness indexes and to adjust taxonomic distinctness to dominance of individual species. Interpreted jointly with taxonomic distinctness indexes from literature, these measures can help to avoid biased conclusion if a single species dominates taxonomic diversity. For example, they may be helpful to scientists which investigate assemblages dominated by introduced plants that bear only little taxonomic resemblance to native vegetation.

\section{Study Area}

\subsection{Geography of South-Central Chile}

South-central Chile (VII. Region del Maule, VIII. Region del Biobio) is the main part of the temperate zone of Chile and extends from $35^{\circ} \mathrm{S}$ to $37^{\circ} \mathrm{S}$. Its climate is a Mediterranean Csb climate (Köppen-Geiger) [19]. The annual mean temperature is around $12^{\circ} \mathrm{C}$ and the mean annual precipitation is about $1300 \mathrm{~mm}$. Morphologically, the zone is structured by the coastal range, which is a mountain range running from NNE to SSW. Towards the east, the Andes represent a high mountain region which forms the borders of the country. In between both mountain ranges the central depression is found. Metamorphic rocks of Palaeozoic age form the basement of the coastal range. Younger (Quaternary and Tertiary) and volcanic material is superimposed from the Andes [20]. 
The two regions cover around $67,358 \mathrm{~km}^{2}$ and are inhabited by over 2,700,000 people. Hence, the population density of around 41 persons per $\mathrm{km}^{2}$ is among the highest of the country [21].

The regions therefore represent a zone of intensive human activity and human modification of the natural environment has been profound. The arrival of European colonists mark the beginning of landscape transformation in which vast parts of the formerly tree-covered zone have been opened by fire clearance [22]. At the same time agriculture began to adopt European practices [23]. It was then, when numerous European herbaceous species have successfully been introduced into the regions [24]. At the end of the 18th century, the first Pinus plantations have been established. At this time, the main goal was to prevent erosion [10] [11]. Plantation establishment has intensified under the Pinochet government when forestry has been strongly promoted due to the neoliberal economic strategy [6] [7]. Investments in forestry were subsidized to $75 \%$ by the Chilean government [25].

For this reason, it has long been claimed that plantations are established exclusively on abandoned fields with soil protection purposes [26]. However, recently remote sensing based studies reveal that to a large extent, native deciduous and sclerophyllous forests have been replaced by plantations indeed. Since native forests are expected to provide the same protection, plantations established on formerly tree covered sites cannot be considered a justified measure for soil protection. Deforestation was strongest between 1975 and 1990 [1] [14].

Nowadays, vast parts of the coastal range are covered with commercial forestry plantations. Pinus radiata D. Don is by far the most frequent tree species followed by Eucalyptus globulus Labill. Other tree species-like Populus nigra L.- - are also planted, but cover less than one percent of the regions. Only a few percent of the region remain tree covered (own data, unpublished). It can be stated, that intensive replacement of native forests by commercial tree plantations has taken part.

However, the effects of this process on biodiversity remain largely unclear. To the authors best knowledge, studies on the effects of plantation forestry on biodiversity of plants, which are based on systematic assessments exists only for Patagonia [27] [28]. Studies on taxonomic diversity of forest plantations in Chile have not been published.

\subsection{Plant Formations Investigated}

Five plant formations are investigated in this study. Two of them represent native forests and three of them are plantations with different tree species. The first forest type is the deciduous Maulino forest which is dominated by Nothofagus glauca Phil. Krasser and Nothofagus obliqua Mirb. Blume. The forests consist of one or two tree strata followed by an under-storey of multiple shrub and herbaceous strata. Within the under-storey, many native and endemic species like Aristotelia chilensis (Molina) Stuntz, Escallonia pulverulenta (Ruiz \& Pav.) Pers., Eccremocarpus scaber Ruiz \& Pav or Gevuina avellana Molina are typical [29]-[31]. The second forest type is built up by sclerophyllous tree species like C. alba, P. boldus and L. caustica. These forests also consist of one or two tree strata and an under-storey of multiple shrub and herbaceous strata. Typical native and endemic species of the tree or under-storey strata are Quillaja saponaria Molina, Sophora macrocarpa J. E. Sm. or Schinus molle L. [29] [32].

Since the study area represents an ecotone between deciduous and sclerophyllous forests, it is common to find some species from one forest type appear in the other forest type as well. As stated above, both forest types are increasingly threatened by the extension of commercial plantation with non-native trees. Plantations are highly managed ecosystems that consist of a single tree, usually as equal aged cohorts. The under-storey below trees is sparsely vegetated and inhabited by only a few species and the same accounts for the herbaceous stratum.

Plantations are harvested after 10 to 25 years by clear-cutting of the entire plantation. Herbicides are applied after clear-cutting and before planting. At least in the past, plantations were burned after clear-cutting [9] [33]. Biodiversity of under-storey strata in plantations divers with the tree species planted. According to field knowledge, more species appear in the under-storey of E. globulus than under P. nigra and even less under $P$. radiata. Furthermore, species composition below plantations is frequently dominated by introduced shrubs like Teline monspessulana (L.) K. Koch, Rubus ulmifolius L. or Rosa rubiginosa Schott.

\section{Measures for Taxonomic Diversity from Literature}

Measures for taxonomic diversity have been published by [18] [34]-[36]. The key idea is that biodiversity should not merely be defined and analysed on the species level, but to include higher taxonomic ranks into the analysis [37]. Various measures for this goal have been published in literature. 


\subsection{Taxonomic Diversity}

Taxonomic diversity $\Delta$ presented in Equation (1) computes the taxonomic relatedness of all pairs of two species in an assemblage [35]. $x_{i}$ and $x_{j}$ are numeric representations of the species abundances (e.g. numbers of individuals) and $n$ is the sum of these abundances (i.e. $n=\sum x_{i}$ ). A distinctness weight $\omega_{i j}$ is introduced which is a representation of the path length linking two species. For instance, given $t=4$ taxonomic ranks (class, order, family and genus), two species $i$ and $j$ may yield $\omega_{i j}=4$ if they are in the same class, $\omega_{i j}=3$ if they are in the same class and order and $\omega_{i j}=1$ if they are even in the same genus. However, other sorts of weights are possible [36] [38]. By dividing the double sum in Equation (1) through $[n(n-1) / 2]$ an arithmetic mean value is produced. Note that $\Delta$ cannot be applied to relative abundance values. Since relative abundances sum up to one $\left(n=\sum x_{i}=1\right)$, the denominator becomes $[n(n-1) / 2]=[1(1-1) / 2]=0$ and hence, Equation (1) is not defined.

$$
\Delta=\left[\sum_{j=1, \cdots, n} \sum_{i<j} \omega_{i j} x_{i} x_{j}\right] /[n(n-1) / 2]
$$

\subsection{Taxonomic Distinctness}

Taxonomic distinctness $\Delta^{*}$, as defined in Equation (2) is a slightly different measure for comparing taxonomic relatedness in assemblages of species [35]. It can be applied to relative abundances since its denominator $\sum x_{i} x_{j}$ sums up to one if relative abundance values are used. Since the numerator and denominator of Equation (2) are differ only by $\omega_{i j}, \Delta^{*}$ is a meaningful arithmetic mean of $\sum \sum \omega_{i j} x_{i} x_{j}$.

$$
\Delta^{*}=\left[\sum_{j=1, \cdots, n} \sum_{i<j} \omega_{i j} x_{i} x_{j}\right] /\left[\sum_{j=1, \cdots, n} \sum_{i<j} x_{i} x_{j}\right]
$$

\subsection{Weighting of the Linking Path}

As stated above, for an analysis of $t=4$ taxonomic ranks, $\omega_{i j}$ can simply be the rank $v$ two species share counting from $\mathrm{t}$ to 1 . In this case, $\Delta \approx 2$ states that the mean relatedness between species is on the family level. Taxonomic diversity is thus compared to a scale of $[1, \mathrm{t}]$. However, measures like $\Delta$ and $\Delta^{*}$ are very flexible with respect to the input data $x_{i}$ and $\omega_{i j}$. Therefore, different weights for the linking path length can be defined [36] [38]. For instance, one could wish to measure taxonomic diversity of a scale of [0,100]. This can be done by dividing 100/v, $v \in[1, t]$. For four taxonomic ranks, $\omega_{i j}$ can then take the values $\omega_{i j} \in[100 / 1$, $100 / 2,100 / 3,100 / 4]=[100,50,33.3,25]$. This weighting is used within this study and produces a percentages index of taxonomic diversity.

\section{Measures for Taxonomic Dominance and Modified Taxonomic Distinctness}

\subsection{Motivation for Modifying Measures}

Measures for taxonomic distinctness have successfully been applied for vegetation data by [39] [40]. Within this section, the rational for modifying taxonomic distinctness shall be outlined. Consider an analysis on taxonomic diversity which covers $t=8$ taxonomic ranks and $n=5$ species $^{1}$. For assemblage A four species share the lowest taxonomic rank (e.g. genus). The fifth is an introduced specie from another floristic region or geoelement and related to the others only at the highest taxonomic rank (e.g. subdivison). For simplicity, assume that all species are equally abundant (i.e. $x_{i}=1 / n=0.2$ and thus $x_{i} x_{j}=0.2^{2}=0.04, \forall \mathrm{I}=1, \ldots, \mathrm{n}$ ).

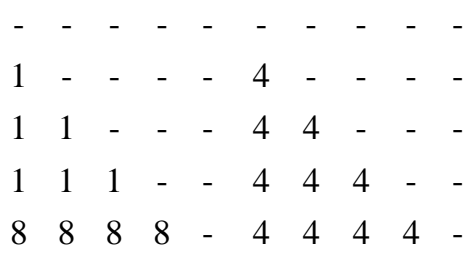

The matrix for $\omega_{i j}$ for assemblage A is given in the left part of Equation (3) and $\Delta^{*}=[(6 \times 1 \times 0.04)+(4 \times$

${ }^{1}$ Such a situation is not a hypothetical example at all. For an assemblage which contains both conifers and deciduous trees one may easily cover nine taxonomic ranks (from subdivision to specie) if full taxonomic hierarchy is considered. 
$8 \times 0.04)] /(10 \times 0.04)=3.8$.

Now imagine an assemblage B where all species share only the fourth taxonomic rank. For simplicity, again all species are equally abundant. The matrix for assemblage $\mathrm{B}$ is shown in the right part of Equation (3) and $\Delta^{*}=[(10 \times 4 \times 0.04)] /(10 \times 0.04)=4.0$. Thus, $\Delta_{A}^{*}$ and $\Delta_{B}^{*}$ are comparable although in assemblage A all but one species share the lowest taxonomic rank (which may be the genus) and in assemblage Ball species are in the fourth taxonomic rank, which is significantly higher, since it may be even the class. It may be argued that the taxonomic distinctness of $\mathrm{A}$ is actually lower than suggested by $\Delta_{A}^{*}$ because it is dominated by one species while all the others are even in the same genus. And thus, $\Delta_{A}^{*}$ could be considered biased towards a single species. Taxonomic distinctness is not evenly distributed over the species of assemblage A. Instead taxonomic dominance of an individual specie is observed. Of course, one may exclude the dominant species from the diversity record of assemblage A. By doing so $^{2}, \Delta_{A}^{*}$ would drop to $\Delta_{A}^{*}=[(6 \times 1 \times$ $0.00625)] /(10 \times 0.00625)=1$. However, this exclusion seems arbitrary. Furthermore, in case of more than one dominant species, no protocol exists on how many and which species to exclude.

One may thus be interested in finding impartial criteria which indicate the relative contributions of species. These criteria may then be used to identify species which are dominant and to estimate taxonomic distinctness while taking account of this dominance. Mathematical foundations for such criteria are proposed in the following.

\subsection{Relative Contribution of Individual Species}

The relative contribution of individual species to taxonomic distinctness $\Delta^{*}$ is computed as follows. At first, the marginal distribution is needed. The marginal distribution is defined as $\rho_{i}=\sum_{i \neq j} \omega_{i j} x_{i} x_{j} \cdot \rho_{i}$ is a $1 \times \mathrm{n}$ vector. The relative contribution of species to $\Delta^{*}$ are computed according to Equation (4).

$$
\tau_{i}=\rho_{i} / \sum_{i=1, \cdots, n} \rho_{i}
$$

A high value of $\tau_{i}$ indicates, that the respective specie contributes more strongly to taxonomic distinctness $\Delta^{*}$ than other species in its assemblage do. Thus, $\tau_{i}$ may be used to assess the taxonomic dominance of individual species and the taxonomic evenness of an assemblage of species as will be shown in Section 6 .

However, a clear distinction has to be made at this point. In species-oriented biodiversity research, dominance relates to the fact that one specie is much more abundant (e.g. in terms of individuals or relative abundance) than others and thus focuses on the contribution of organisms of one species to all organisms of an assemblage. In contrast, taxonomic dominance relates to the fact that an individual species dominates the measures for taxonomic diversity. Thus, a high value of $\tau_{i}$ addresses the fact specie $i$ contributes strongly to the index $\Delta^{*}$. Although this semantic divergence is a potential source of confusion, it seems reasonable to adhere to it. This is due to the fact that similar divergence exists between the terms species diversity and taxonomic diversity. Species diversity, as assessed e.g. by the Simpson diversity index [41] $S_{D}=1-\sum x_{i}^{2}$, measures the relative contribution $x_{i}$ of a specie $i$ to the assemblage. Taxonomic distinctness, as assessed by $\Delta^{*}$, measures the relative contribution $\omega_{i j}$ of a specie $i$ to the overall diversity of taxa. For this reason, if taxonomic hierarchy is ignored (i.e. $\omega_{i j}=1$ ), $\Delta$ approximates the Simpson diversity index [35] [42].

For this circumstances, the notion of taxonomic dominance relates to the notion of standard dominance in a similar fashion as taxonomic diversity relates to standard diversity which justifies using this nomenclature.

\subsection{A Measure for Taxonomic Dominance of an Assemblage}

After deriving the relative contributions $\tau_{i}$ of individual species, it may now be helpful to derive an index for the taxonomic evenness of an entire assemblage of species. Such an index should indicate, whether the species of the assemblage contribute evenly to taxonomic diversity or whether single species dominate the taxonomic diversity of the assemblage. This is the case in assemblages which consist of a few native species that are all from the same family and one introduced species from a different class or order for example. Such a measure for taxonomic evenness may simply be derived from statistical concentration indexes.

$$
C=\prod_{i=1, \cdots, n} \tau_{i}^{\tau_{i}}
$$

${ }^{2}$ When considering the computation, it has to be kept in mind, that due to exclusion of the dominant specie, $n=4$ and thus $x_{i}=1 / n=0.25$ and $x_{i} x_{j}=0.00625$ 
Such an index for concentration is given by the exponential index $C$. The exponential index for $\tau_{i}$ values is given in Equation (5). $C$ is bounded by $C \in[1 / n, 1]$. Due to this dependence of $C$ on $n$ it has to be rescaled to $C_{\mathrm{EI}} \in[0,1]$ which is done by $C_{\mathrm{EI}}=(C-1 / n) /(1-1 / n)$. Note that $C_{\mathrm{EI}}$ is very sensitive to concentration effects in $\tau_{i}$. From $C_{\mathrm{EI}}$, an index for the taxonomic evenness of the entire assemblage may by derived according to $\varepsilon=1-C_{\mathrm{EI}}$. A high value indicates that taxonomic distinctness is evenly distributed over the $\mathrm{n}$ species, a low index indicates that some species dominate the taxonomic distinctness of the assemblage. Thus, $\Delta^{*}$ can be converted to take account of dominance by $\Delta_{\varepsilon}^{*}=\varepsilon \cdot \Delta^{*}$. It should be noted that $\Delta^{*}$ and $\Delta_{\varepsilon}^{*}$ are similar to pairs of diversity and evenness indexes from species-oriented biodiversity research (e.g. the Simpson diversity index and the Simpson evenness measure). Just like these indexes, $\Delta^{*}$ and $\Delta_{\varepsilon}^{*}$ should always be analysed jointly. $\Delta^{*}$ then indicates to which degree the species of an assemblage are taxonomically distinct and $\Delta_{\varepsilon}^{*}$ indicates to which degree this distinctness is due to some individual species in the assemblage which are taxonomically distinct to most others.

\subsection{Vegetation Assessments}

For the analysis of taxonomic distinctness, 75 vegetation assessments taken during a field campaign in 2012 are used. There are 15 assessments of each type of plant formation under consideration, i.e. plantations of $P$. radiata, plantations of $E$. globulus, plantations of $P$. nigra, sclerophyllous forests with the main tree species C. alba and deciduous forests with the main tree species $N$. obliqua. Assessments were done following the method of J. Braun-Blanquet [43]. In order to be able to compute taxonomic distinctness $\Delta^{*}$ with relative abundance values, Braun-Blanquet abundance values were transformed into relative abundances according to the method of [44]. A species with a Braun-Blanquet abundance value of e.g. 2 has a cover between 25\% and $50 \%$. Its cover is averaged to $r_{i}$, where $r_{i}=(0.25+0.5) / 2=0.375$. Other Braun-Blanquet abundance values were transformed accordingly. Species with a value of + were given $r_{i}=0.025$ and species with $r$ were given $r_{i}=0.00625$. Then, the relative abundance of a species is calculated as $p_{i}=r_{i} / \sum r_{i}$.

The species found in these assessments were than classified into the taxonomic ranks: kingdom, subkingdom, infrakingdom, division, subdivision, infradivision, class, subclass, superorder, order, family, genus and species. The Integrated Taxonomic Information System ITIS is used (www.itis.gov). For simplicity, abbreviations for the five plant formations are introduced: $\mathrm{fDC}=$ deciduous forest, $\mathrm{fSC}=$ sclerophyllous forest, $\mathrm{pPR}=$ plantation of $P$. radiata, $\mathrm{pEG}=$ plantation of $E$. globulus and $\mathrm{pPN}=$ plantation of $P$. nigra .

\section{Results}

\subsection{Taxonomic Richness}

At the beginning of the assessment, taxonomic richness of the five plant formations is analysed. Taxonomic richness is understood as the number of taxa of each taxonomic rank represented in the assessments of each plant formation. Indexes for taxonomic richness give an overview on the conditions of taxonomic diversity within the plant formations assessed. Figure 1 shows a plot of the results. Results attest the highest taxonomic richness to deciduous forests and the second highest to sclerophyllous forests. The three plantation types show a lower taxonomic richness at each taxonomic rank. There is no taxonomic rank which yields a higher taxonomic richness within any plantation type than within forests. Among the plantations, the $E$. globulus type yields higher taxonomic richness values than the other types. The $P$. radiata type yields the lowest taxonomic richness values of all plantations and thus, of all formations investigated. As can further be seen, no formation contains more than one taxon within the first four taxonomic ranks (kingdom to division). Since they contain only redundant information, the first three ranks will be excluded from further analyses.

\subsection{Taxonomic Diversity of Plant Formations}

As a next step, the overall taxonomic diversity $\Delta$ of the 15 assessments of each of the five plant formations is analysed. For this purpose, taxonomic diversity $\Delta$ values are computed according to Equation (1). For the abundance values $x_{i}$, frequencies were used, $x_{3}=7$ thus states that the third specie occurs in seven of the 15 plots of the respective plant formation. For $\omega_{i j}$ the weighting described in Section 4.3 is used. An overview of the results is provided in Table 1 . As can be seen, for overall taxonomic diversity $\Delta$, a similar ranking is 


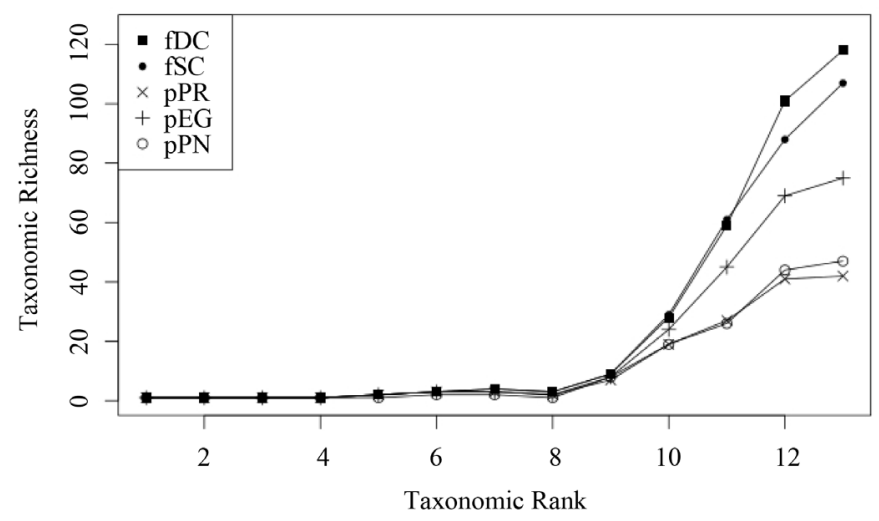

Figure 1. Taxonomic richness at each taxonomic rank.

Table 1. Overall taxnonomic diversity $\Delta$ of the five plant formations.

\begin{tabular}{ccccc}
\hline Plant Formation & Symbol & $\Delta$ & Rank & Rad. To fDC \\
\hline fDC & $\boldsymbol{0}$ & 82.70 & 1 & - \\
fSC & $\bullet$ & 81.75 & 2 & 0.95 \\
pPR & $\times$ & 65.54 & 3 & 17.16 \\
pEG & + & 77.38 & 4 & 5.32 \\
pPN & 0 & 73.66 & 5 & 9.04 \\
\hline
\end{tabular}

observed as for taxonomic richness (cf. Section 6.1). Deciduous forest are the most diverse plant formation followed by sclerophyllous forest. Among plantations, the E. globulus type is most diverse and the $P$. $r a-$ diata type is the least diverse. $P$. radiata plantations are over 17 percent agesless diverse than deciduous forests. Table 1 reveals pronounced reductions of overall taxonomic diversity between plantations and forests. However, since all 15 plots of each plant formations are aggregated to a single value of $\Delta$, statistical tests which would allow to prove the significance of these findings are not possible at this point.

\subsection{Taxonomic Distinctness of Individual Assessments}

In order to test the significance of the differences documented, taxonomic distinctness is now computed for each vegetation assessment individually. For this purpose, $\Delta^{*}$ is computed (cf. Equation (2)). Instead of using the frequency of a specie over 15 assessments, the relative abundance $p_{i}$ derived from the Braun-Blanquet abundance values of a specie in a single plot is used as $x_{i}$ to compute $\Delta^{*}$. Besides this important difference, the processing is the same as in Section 6.2, i.e. the same taxonomic ranks and the same weighting $\omega_{i j}$ is used.

Boxplots for the $15 \Delta^{*}$ values are produced for each of the five plant formations (cf. Figure 2). Basically, the same ranking for $\Delta^{*}$ is found as for overall taxonomic diversity $\Delta$ in Section 6.2 and taxonomic richness in Section 6.1.

However, there is one important exception. Plantations of $P$. radiata now show the highest values of taxonomic distinctness; their mean value is even higher than for deciduous forests. The significance of these findings is now assessed using a Student's both sided t-Test with a confidence level of 0:05. The null hypothesis of no significant difference in the $\Delta^{*}$ values of two plant formations is tested against the alternative hypothesis of a significant difference. Results are summarized in Table 2. Results confirm that the differences are significant for each pairtested. They furthermore indicate that $P$. radiata plantations are taxonomically more diverse than forests; a finding which is contradictory to previous results and to field experience.

\subsection{Taxonomic Dominance of Individual Species}

In order to clarify the unexpectedly high values of $\Delta^{*}$ in plantations of $P$. radiate in contrast to deciduous and 


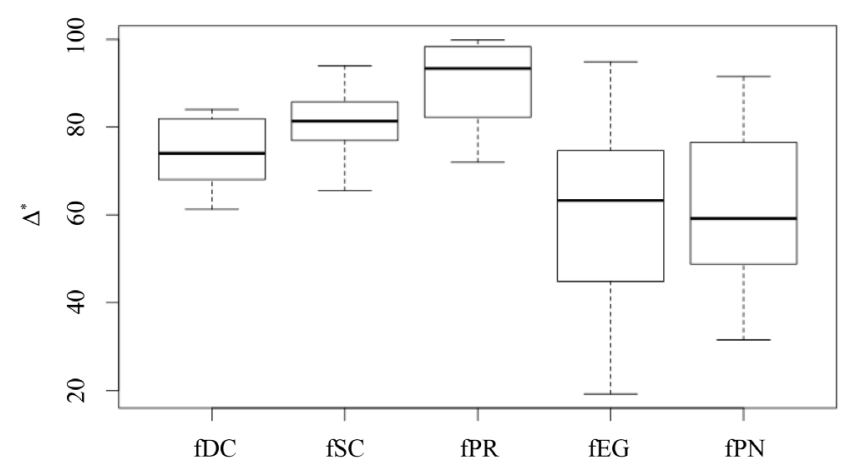

Figure 2. Taxonomic distinctness: $\Delta^{*}$.

Table 2. Results of Student's t-Test on differences in $\Delta^{*}$.

\begin{tabular}{cccc}
\hline & \multicolumn{2}{c}{ Plantation Formation } & \\
\hline Forest Formation & $\mathrm{pPR}$ & $\mathrm{pEG}$ & $\mathrm{pPN}$ \\
\hline fDC & $\mathrm{H} 1(\mathrm{p} \approx 0.000)$ & $\mathrm{H} 1(\mathrm{p} \approx 0.028)$ & $\mathrm{H} 1(\mathrm{p} \approx 0.013)$ \\
fSC & $\mathrm{H} 1(\mathrm{p} \approx 0.011)$ & $\mathrm{H} 1(\mathrm{p} \approx 0.001)$ & $\mathrm{H} 1(\mathrm{p} \approx 0.000)$ \\
\hline
\end{tabular}

sclerophyllous forests, vegetation assessments of both are compared individually. Taxonomic dominance values $\tau_{i}$ are computed which show the relative contribution of single species to $\Delta^{*}$. Figure 3 shows the comparison of a typical plantation of $P$. radiata and a typical assessment of a deciduous $N$. obliqua forest. As can be seen, the $P$. radiata plantation inherits four species, among them, one has a $\tau_{i}$ of around 0.5 , indicating that this specie contributes $50 \%$ to the value of $\Delta^{*}$. The plantations yield a taxonomic distinctness of $\Delta^{*} \approx 99 \%$. The dominant species, explaining $50 \%$ of taxonomic distinctnessis $P$. radiata. This is not surprising. Since $P$. radiata belongs to the infradivision Gymnospermae, while all other species belong the the infradivison Angiospermae, its individual distinctness to other species in the assemblage is high. The other species all belong to the family Rosaceae, i.e. taxonomic distinctness between all species except $P$. radiata is rather low. In contrast, within the forest, all species yield $\tau_{i}$ values below 0.1 . The assemblage is much more even concerning its taxonomic distinctness. Many species contribute to the value of $\Delta^{*} \approx 60 \%$. Incontrast to the plantation, no single species is especially dominant and many taxa are present that resemble each other only on higher taxonomic ranks.

It may be argued at this point that choosing only two assessments for such a comparison is hardly convincing since the high contribution of $P$. radiata could be coincidence. Therefore, the mean $\tau_{i}$ value of $P$. radiata in the15 plantation assessments is computed. It yields a value of $\tau_{i}=47 \%$ stating that the assessment shown in Figure 3 is representative. Furthermore, the mean $\tau_{i}$ values of each of the 123 species found in 15 deciduous forests are computed. The highest mean $\tau_{i}$ obtained for an individual specie is $\tau_{i}=11 \%$ which is yielded by $E$. scaber from the family Scrophulariaceae, a native climber which is frequent within south-central Chile. Hence, the comparison shown within this section is valid.

\subsection{Dominance-Adjusted Distinctness of Individual Assessments}

In the previous section, it has been shown, that the dominance of one individual species (P. radiata) strongly contributes to the high values of $\Delta^{*}$ observed for $P$. radiata plantations in Section 6.3. In order to take account of this dominance, values of $\Delta^{*}$ are adjusted for taxonomic dominance within this section. The concentration factor $C_{\mathrm{EI}}$ is computed on the basis of $\tau_{i}$ values for individual contributions of species. $C_{\mathrm{EI}}$ values are plotted in Figure 4. As can be expected from the results on taxonomic dominance of individual species, plantations of $P$. radiata show higher values of $C_{\mathrm{EI}}$ than all other formations. This finding indicates that the contribution of individual species on taxonomic distinctness $\Delta^{*}$ is more strongly concentrated. Thus, individual species- $P$. radiata in this special case-dominate the $\Delta^{*}$ values. Hence, $\Delta^{*}$ is now adjusted for dominance according to $\Delta_{\varepsilon}^{*}=\varepsilon \cdot \Delta^{*}$ with $\varepsilon=1-C_{\mathrm{EI}}$. Values of $\Delta_{\varepsilon}^{*}$ are plotted in Figure 5 . As can be seen, 


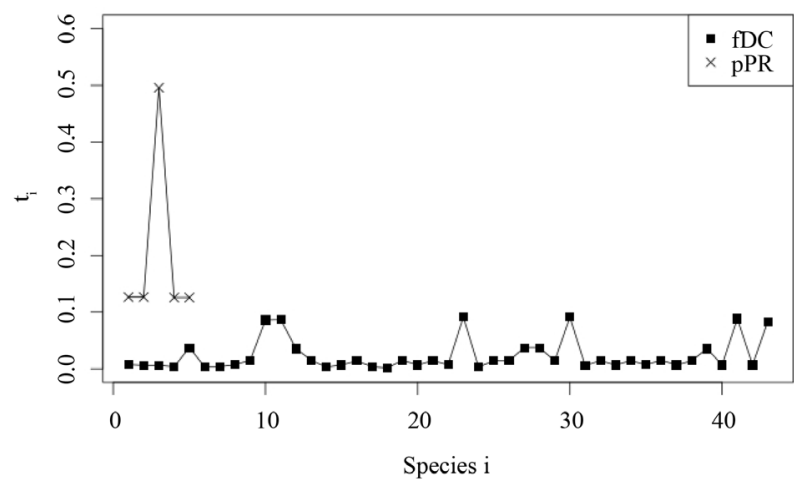

Figure 3. Taxonomic dominance values $\tau_{i}$.

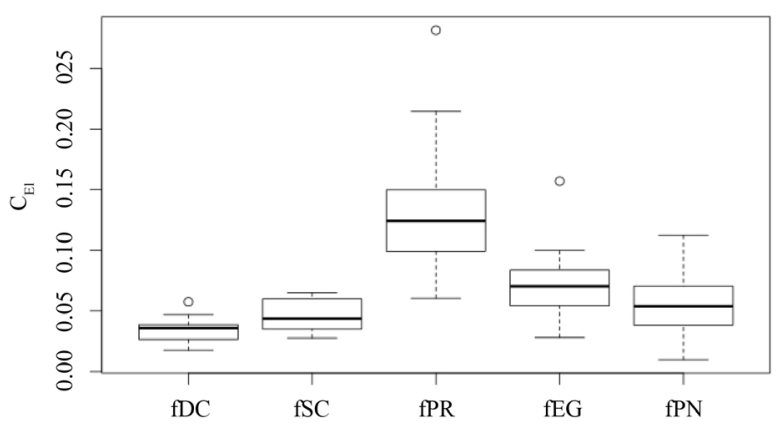

Figure 4. Concentration of taxonomic distinctness: $C_{\mathrm{EI}}$.

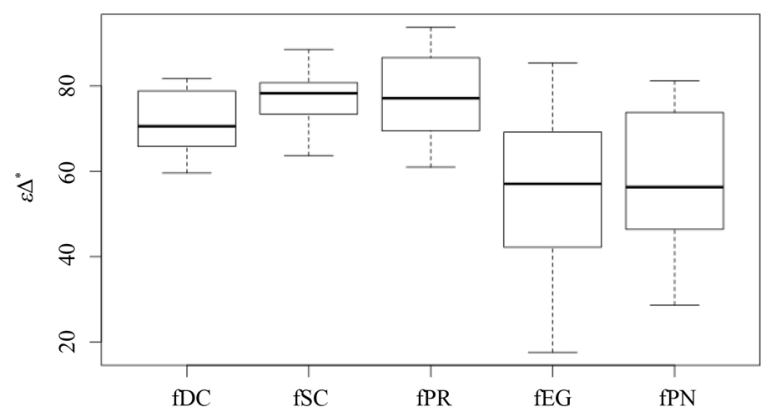

Figure 5. Adjusted taxonomic distinctness: $\varepsilon \Delta^{*}$.

plant formations not strongly affected by taxonomic dominance of individual species do not greatly differ in taxonomic distinctness. Values for $\Delta^{*}$ and $\Delta_{\varepsilon}^{*}$ are comparable for deciduous forests, sclerophyllous forests and plantations of E. globulus and P. nigra. However, for plantations of P. radiata, the value of $\Delta_{\varepsilon}^{*}$ is considerably lower than $\Delta^{*}$, as could be expected. Consequently, the ranking of taxonomic distinctness of $\Delta_{\varepsilon}^{*}$ is more comparable to the ranking of taxonomic diversity $\Delta$ and taxonomic richness. A second set of Student's t-Tests is carried through and summarized in Table 3. According to these results, the differences of taxonomic distinctness between plantations of $P$. radiata and forests are no longer significant and thus, not contradictory to other results any more. For all other comparisons, the conclusion on significance does not alter; the null hypothesis can still be rejected after adjusting for taxonomic dominance.

\subsection{Relationship between Taxonomic Distinctness and Simpson Diversity}

In order to relate conclusions drawn on taxonomic distinctness to species-oriented biodiversity research, taxonomic distinctness values $\Delta_{\varepsilon}^{*}$ are compared to Simpson diversity values $S_{\mathrm{D}}$. Values are plotted in Figure 6. As can be seen, there is a clear distinction between native forests and plantations. With few excep- 
Table 3. Results of Student's t-Test on differences in $\Delta_{\varepsilon}^{*}$.

\begin{tabular}{cccc}
\hline & \multicolumn{2}{c}{ Plantation Formation } & \\
\hline Forest Formation & $\mathrm{pPR}$ & $\mathrm{pEG}$ & $\mathrm{pPN}$ \\
\hline fDC & $\mathrm{H} 0(\mathrm{p} \approx 0.690)$ & $\mathrm{H} 1(\mathrm{p} \approx 0.007)$ & $\mathrm{H} 1(\mathrm{p} \approx 0.005)$ \\
fSC & $\mathrm{H} 0(\mathrm{p} \approx 0.880)$ & $\mathrm{H} 1(\mathrm{p} \approx 0.000)$ & $\mathrm{H} 1(\mathrm{p} \approx 0.000)$ \\
\hline
\end{tabular}

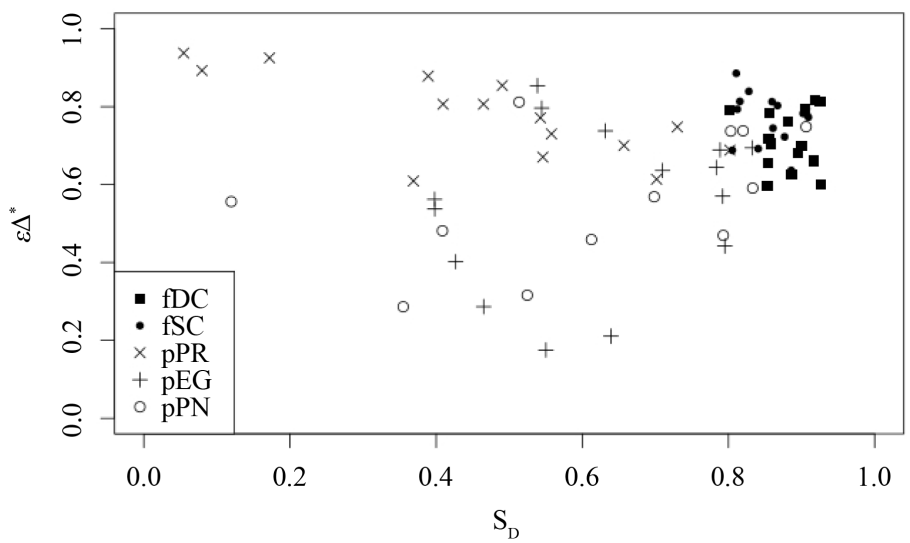

Figure 6. Comparison between taxonomic distinctness $\varepsilon \Delta^{*}$ and Simpson diversity $\mathrm{S}_{\mathrm{D}}$.

tions, plantations assessments show considerably lower values of both taxonomic distinctness and Simpson diversity. No clear distinction with respect to Simpson diversity between plantations can be made. However, due to taxonomic dominance of $P$. radiata, plantations of this type have higher taxonomic distinctness values than other plantations do. Furthermore, it should be noted that values for $\Delta_{\varepsilon}^{*}$ and $S_{\mathrm{D}}$ scatter in a wide range, their correlation coefficient is only $r \approx 0.11$. Thus, no strong correlation between both can be observed.

\section{Discussion}

At first, results will be discussed with respect to regional aspects of biodiversity. Afterwards, a theoretical discussion will be held. Taxonomic richness in the study area in south-central Chile is very high. In 15 vegetation assessment of deciduous forests, 118 species in 59 families are found. Sclerophyllous forest bear only slightly less taxa. This circumstance shows that south-central Chile actually qualifies as a biodiversity hotspot [15].

However, deciduous and sclerophyllous forests inherit many more taxa than plantations. E. globulus plantations maintain the highest levels of taxonomic richness within all plantation types. In contrast, the $P$. radiata type is most impoverished in terms of taxonomic richness. Plantations of $P$. radiata and $P$. nigra inherit only around $40 \%$ of forests richness in species, less than $45 \%$ of the richness of genera and families, only around $67 \%$ of the richness in orders are present in these plantations. Similar results are found for the overall taxonomic diversity $\Delta$ of the five plant formations based on occurrence frequencies. Deciduous forest produce highest $\Delta$ values. Around $83 \%$ of taxonomic diversity are found. This high value underlines again that south-central Chile is a biodiversity hotspot. Sclerophyllous forest are slightly less rich. Overall taxonomic diversity is reduced between 5 and17 percentages in contrast to deciduous forests. Among plantations, E. globulusis more diverse than $P$. nigra and $P$. radiata. The reduction of around 17 percent ages in overall taxonomic diversity within plantations is alarming and emphasizes the need for a more efficient biological conservation program in south-central Chile [4] [5] [45] [46]. In general terms, taxonomic distinctness $\Delta^{*}$ of individual assessments based on relative abundances produces similar tendencies. The ranking of the plant formation remains unchanged with one important exception. P. radiata plantations show the highest $\Delta^{*}$ values of all plant formations. While forests have a significantly higher $\Delta^{*}$ than plantations of $E$. globulus and $P$. nigra, plantations of $P$. radiate have significantly higher values than both forest types. This re- 
sult-although formally and mathematically correct-seems to contradict previous findings. Thus, the conclusion on taxonomic diversity within plantations may seem confusing. In order to clarify this contradictory finding, contributions $\tau_{i}$ of individual species to $\Delta^{*}$ are analyzed. It is shown, that the plantation tree contributes up to $50 \%$ to the value of taxonomic diversity. Due to the fact, that $P$. radiata belongs to the Gymnospermae, while most other species belong to Angiospermae, this high value is not surprising. $P$. radiata is taxonomically dominant in the sense that it explains most of the high value of $\Delta^{*}$. It may be argued that this finding is natural and should be accepted as it is. However, it has to be kept in mind that $\Delta^{*}$ states that plantations are a taxonomically diverse formation. In fact, many $P$. radiata plantations consist of the plantation trees with few and dispersed shrubs below, which may all belong even to the same family. Thus, at least, $\Delta^{*}$ should not be the only index taken into account when discussing findings on taxonomic diversity. For this purpose, concentration effects as formally described by the rescaled exponential index $C_{\mathrm{EI}}$. It is shown, that plantations of $P$. radiata are much more concentrated in their $\Delta^{*}$ values than all other formations. This fact is accounted for by multiplication with of $\Delta^{*}$ with $\varepsilon=1-C_{\mathrm{EI}}$. These dominance-adjusted values $\Delta_{\varepsilon}^{*}$ are computed. As is shown, four of the five plant formations not affected strongly by taxonomic dominance, do not greatly alter their value. Their ranking remains unchanged and statistical tests draw the same conclusions on significance. Thus, the method is robust in the sense that conclusions on these formations remain unchanged. However, for plantations of $P$. radiata $\Delta_{\varepsilon}^{*}$ is lower than $\Delta^{*}$ and inconsequence, the differences between these plantations and forests are no longer significant. Finally, taxonomic distinctness $\Delta_{\varepsilon}^{*}$ is compared to the Simpson index $S_{D}$. This is done to unify the perspective on taxonomic diversity with species-oriented biodiversity. As is shown, two clusters can be observed when plotting both values. The two forest types are clearly separated from plantations, but not from each other. Plantations can hardly be separated on the basis of $S_{\mathrm{D}}$. However, as discussed above, $\Delta_{\varepsilon}^{*}$ is higher for P. radiata. $\Delta_{\varepsilon}^{*}$ and $S_{\mathrm{D}}$ draw an accordant picture on biodiversity effects of plantation forestry. Plantation forestry lowers species-oriented biodiversity and taxonomic diversity. However, correlation between $\Delta_{\varepsilon}^{*}$ and $\mathrm{S}_{\mathrm{D}}$ is rather low. Concerning the theoretical aspects of biodiversity aspect, it can be stated that the literature published on taxonomic diversity by [18] [34]-[36] provides valuable indexes when analyzing biodiversity impacts of Chilean forest plantations. The conclusions derived from $\Delta$ and $\Delta_{\varepsilon}^{*}$ confirm the field experience of the authors. There is a discussion in literature on whether taxonomic diversity indexes are more robust than species-oriented biodiversity indexes [35] [47] [48]. On the basis of the findings within this study, no definite decision on this research question can be given. This is because indexes for taxonomic diversity and Simpson diversity are equally robust and draw the same image on impacts on biodiversity. However, it can be clearly stated, that indexes for taxonomic diversity produce additional information which is not represented by species-oriented indexes. Correlation with the Simpson diversity index $S_{D}$ is not very high. Thus, the information in $\Delta_{\varepsilon}^{*}$ is not redundant. For this reason, taxonomic diversity complements species-oriented biodiversity research and introduces a new perspective. Thus, it is recommended to incorporate indexes on taxonomic diversity into biodiversity assessments. While taxonomic diversity $\Delta$ confirms the findings of taxonomic richness, Simpson diversity and field experience straightforwardly, $\Delta^{*}$ may be the source of some confusion. It attests a high taxonomic distinctness to the plant formations which is least diverse according to field experience. It is shown that this fact comes from the taxonomic dominance of a single specie which overwhelms the contributions of other species. Taxonomic dominance can be identified with $\tau_{i}$. In plots over all species $\tau_{i}$ shows the dominance or evenness of the entire assemblage. At this point, it should be noted, that evenness can also be addressed by the variance of taxonomic distinctness indexes like $\Delta^{*}$ in [47]. While, $\Delta^{*}$ allows to draw conclusion on the entire assemblage, it does not allow to attribute variance to individual species as $\tau_{i}$ does. Furthermore, concentration as described by the rescaled exponential index $C_{\mathrm{EI}}$ can be accounted for by $\varepsilon$. This adjustment allows to take account of some of the bias in $\Delta_{\varepsilon}^{*}$ to taxonomic dominance of $P$. radiata. However, total agreement between $\Delta_{\varepsilon}^{*}$ and other values like $\Delta$ or taxonomic richness is not achieved. A possible solution could be to more strongly adjust for concentration effects. However, on the basis of the mathematical foundations, there is no justification to do so. For instance, adjusting by the doubled value of $\varepsilon$ may lower taxonomic distinctness even more, but cannot be formally motivated. $\Delta$ and $\Delta_{\varepsilon}^{*}$ are not derived from sophisticated mathematics, rather, they are derived from standard statistical figures (namely marginal distributions and the exponential index). This simplicity, at the same time, can be considered an advantage. Within this study, only values of $\Delta^{*}$ are analyzed and adjusted with the methodology developed. However, values for $\Delta$ 
or $\Delta^{+}$[18] can be modified analogical. Despite the simplicity, figures developed are helpful to cast some light on ostensible contradictions and can help to clarify the meaning of $\Delta^{*}$ values. Thus, is recommended to not only base analyses on taxonomic diversity to just one index. Instead, a variety of indexes on overall diversity of plant formations, individual assessments and individual species should be taken into account in order to produce a multifaceted and concordant image. $\Delta_{\varepsilon}^{*}$ should be computed in addition to $\Delta^{*}$ in order to control for taxonomic dominance. It should be stated, though, that $\Delta_{\varepsilon}^{*}$ may be helpful only in very special situations. Namely in situations, where single species are dominant in assessments and only related at high taxonomic ranks with most other species. Such situations maybe given when analyzing agricultural, agroforestal or forestal productive systems. Moreover, they may be given in the case of plant invasions with species that bear only little taxonomic relatedness to native vegetation.

\section{Conclusion}

This study analyses the impact of plantation forestry on plant biodiversity in south-central Chile by comparing taxonomic diversity in plantations and native forests. Two forest types and three plantation types are assessed, each represented by 15 vegetation assessments. It is shown, that numbers of taxa in taxonomic ranks, taxonomic diversity based on species frequencies in all plots, taxonomic distinctness based on relative abundances in individual plots and Simpson diversity values are all remarkably reduced within plantations. For all but one indexes, $P$. radiata plantations yield the lowest biodiversity value by far. As an example, the number of species, genera and families found is some reduced between 55 and 65 percentages than in deciduous Nothofagus sp. forests. Furthermore, taxonomic diversity is 17 percentages lower than in deciduous forests. The usage of taxonomic distinctness values produces some confusion results at first glance. $P$. $r a-$ diata plantations yield the highest values of taxonomic distinctness when using indexes from literature. However, it can be shown that this circumstance is explained by taxonomic dominance of $P$. radiata. Due to the fact that Gymnospermae like $P$. radiata is inherently distinct to other plants which are Angiospermae, high values of taxonomic distinctness are inevitable. This holds true even for plots, where besides $P$. radiata, only three other species are found which are all in the same family. For this reason, indexes are developed which describe and account for taxonomic dominance. Afterwards, the advantage of $P$. radiate plantations in terms of taxonomic distinctness becomes less pronounces and insignificant. At the same time, indexes for other plant formations and conclusions on their biodiversity value remain largely unchanged. Although based on simple statistics, the figures developed herein may contribute to research on taxonomic diversity, especially for cases where productive systems of plant invasions are analyzed. Taxonomic diversity measures do not correlate with standard biodiversity indexes and thus provide new insights into biodiversity. It is therefore concluded that taxonomic diversity should generally be included into biodiversity assessments.

\section{References}

[1] Echeverria, C., Coomes, D., Salas, J., Rey Benayas, J., Lara, A. and Newton, A. (2006) Rapid Deforestation and Fragmentation of Chilean Temperate Forests. Biological Conservation, 130, 481-494. http://dx.doi.org/10.1016/j.biocon.2006.01.017

[2] Smith Ramirez, C. (2004) The Chilean Coastal Range: A Vanishing Center of Biodiversity and Endemism in South American Temperate Rainforests. Biodiversity and Conservation, 13, 373-393. http://dx.doi.org/10.1023/B:BIOC.0000006505.67560.9f

[3] Grez, A., Bustamante, R., Simonetti, J., Fahrig, L., Salinas Chaves, E. and Middleton, J. (1998) Landscape Ecology, Deforestation, and Forest Fragmentation: The Case of the Ruil Forest in Chile. In: Grez, A., Bustamante, R.O., Simonetti, J.A., Fahrig, L., Salinas-Chaves, E. and Middleton, J., Eds., Landscape Ecology as a Tool for Sustainable Development in Latin America, Editorial Universitaria, Santiago de Chile, 1-26.

[4] Altamirano, A. and Lara, A. (2010) Deforestation in Temperate Ecosystems of Pre-Andean Range of South-Central Chile. Bosque, 31, 53-64.

[5] Nahuelhual, L., Carmona, A., Lara, A., Echeverria, C. and Gonzalez, M. (2012) Landcover Change to Forest Plantations: Proximate Causes and Implications for the Landscape in South-Central Chile. Landscape and Urban Planning, 107, 12-20. http://dx.doi.org/10.1016/j.landurbplan.2012.04.006

[6] Altieri, M. and Rojas, A. (1999) Ecological Impacts of Chile’s Neoliberal Policies, with Special Emphasis on Agroecosystems. Environment, Development and Sustainability, 1, 55-72. 
[7] Clapp, R. (1995) Creating Competitive Advantage: Forest Policy as Industrial Policy in Chile. Economic Geography, 71, 273-296. http://dx.doi.org/10.2307/144312

[8] Braun, A.C., Rojas, C., Echeverria, C., Rottensteiner, F., Bähr, H. P., Niemeyer, J., Aguayo Arias, M., Kosov, S., Hinz, S. and Weidner, U. (2014) Design of a Spectral-Spatial Pattern Recognition Framework for Risk Assessments Using Landsat Data-A Case Study in Chile. IEEE Journal of Selected Topics in Applied Earth Observations and Remote Sensing, 7, 917-928.

[9] Clapp, R. (1995) The Unnatural History of the Monterey Pine. Geographical Review, 85, 1-19. http://dx.doi.org/10.2307/215551

[10] Camus, P. and Hajek, E. (1998) Historia ambiental de Chile. Departamento de Ecologia, Facultad de Ciencias Biologicas, Pontificia Universidad Catolica de Chile.

[11] Camus, P. (2003) Federico Albert: Artifice de la Gestion de los Bosques de Chile. Revista de Geografia Norte Grande, 30, 55-63.

[12] Bustamante, R.O. and Castor, C. (1998) The Decline of an Endangered Temperate Ecosystem: The Ruil (Nothofagus alessandrii) Forest in Central Chile. Biodiversity \& Conservation, 7, 1607-1626. http://dx.doi.org/10.1023/A:1008856912888

[13] Cisternas, M., Martinez, P., Oyarzun, C. and Debels, P. (1999) Characterization of the Replacement Processes of Native Vegetation by Forest Plantations in a Lacustrine Watershed in the Nahuelbuta Mountain Range, VIII Region, Chile. Revista Chilena de Historia Natural, 72, 661-670.

[14] Wilson, K., Newton, A., Echeverria, C., Weston, C. and Burgman, M. (2005) A Vulnerability Analysis of the Temperate Forests of South Central Chile. Biological Conservation, 122, 9-21. http://dx.doi.org/10.1016/j.biocon.2004.06.015

[15] Myers, N., Mittermeier, R.A., Mittermeier, C.G., da Fonseca, G.A.B. and Kent, J. (2000) Biodiversity Hotspots for Conservation Priorities. Nature, 403, 853-858. http://dx.doi.org/10.1038/35002501

[16] Braun, A.C. and Vogt, J. (2014) A Multiscale Assessment of the Risks Imposed by Plantation Forestry on Plant Biodiversity in the Hotspot Central Chile. Open Journal of Ecology, 4, 1025.

[17] Myers, N. (2003) Biodiversity Hotspots Revisited. BioScience, 53, 916-917.

[18] Warwick, R.M. and Clarke, K.R. (2003) Taxonomic Distinctness and Environmental Assessment. Journal of Applied Ecology, 35, 532-543. http://dx.doi.org/10.1046/j.1365-2664.1998.3540532.x

[19] Peel, M.C., Finlayson, B.L. and McMahon, T.A. (2007) Updated World Map of the Köppen-Geiger Climate Classification. Hydrology and Earth System Sciences Discussions, 4, 439-473. http://dx.doi.org/10.5194/hessd-4-439-2007

[20] Veit, H. and Garleff, K. (1995) Evolución del paisaje cuaternario y los suelos en Chile central-sur. In: Armesto, J., Villagrán, C. and Arroyo, M., Eds., Ecología de los bosques nativos de Chile, Editorial Universitaria, Santiago, 363-387.

[21] Instituto Nacional de Estadisticas, Compendio Estadistico, 2012.

[22] Aronson, J., Del Pozo, A., Ovalle, C., Avendano, J., Lavin, A. and Etienne, M. (1998) Land Use Changes and Conflicts in Central Chile. In: Rundel, P.W., Montenegro, G. and Jaksic, F., Eds., Landscape Disturbance and Biodiversity in Mediterranean-Type Ecosystem, Springer Verlag, Berlin, 155-168.

[23] Ovalle, C., Aronson, J., Del Pozo, A. and Avendano, J. (1990) The Espinal: Agroforestry Systems of the Mediterranean-Type Climate Region of Chile. Agroforestry Systems, 10, 213-239. http://dx.doi.org/10.1007/BF00122913

[24] Holmgren, M., Avilés, R., Sierralta, L., Segura, A.M. and Fuentes, E.R. (2000) Why Have European Herbs So Successfully Invaded the Chilean Matorral? Effects of Herbivory, Soil Nutrients, and Fire. Journal of Arid Environments, 44, 197-211. http://dx.doi.org/10.1006/jare.1999.0589

[25] Ministerio De Agricultura, Decreto Ley 701. fija Regimen Legal de los Terrenos Forestales o Preferenmente Aptos para la Forestacion, y Establece Normas de Fomento sobre la Materia, 1974.

[26] Toro, J. and Gessel, S. (1999) Radiata Pine Plantations in Chile. New Forests, 18, 33-44. http://dx.doi.org/10.1023/A:1006597823190

[27] Corley, J., Sackmann, P., Rusch, V., Bettinelli, J. and Paritsis, J. (2006) Effects of Pine Silviculture on the Ant Assemblages (Hymenoptera: Formicidae) of the Patagonian Steppe. Forest Ecology and Management, 222, 162-166. http://dx.doi.org/10.1016/j.foreco.2005.09.025

[28] Paritsis, J. and Aizen, M.A. (2008) Effects of Exotic Conifer Plantations on the Biodiversity of Understory Plants, Epigeal Beetles and Birds in Nothofagus dombeyi Forests. Forest Ecology and Management, 255, 1575-1583. http://dx.doi.org/10.1016/j.foreco.2007.11.015

[29] Luebert, F. and Pliscoff, P. (2006) Sinopsis bioclimatica y vegetacional de Chile. Editorial Universitaria, Santiago.

[30] Amigo, J., San Martin, J. and Garcia, L. (2000) Estudio fitosociológico de los bosques de Nothofagus glauca (Phil.) Krasser del Centro-Sur de Chile. Phytocoenología, 32, 193-221. 
[31] Hildebrand-Vogel, R. (2002) Structure and Dynamics of Southern Chilean Natural Forests with Special Reference to the Relation of Evergreen versus Deciduous Elements. Folia Geobotanica, 37, 107-128. http://dx.doi.org/10.1007/BF02803194

[32] Donoso, C. (1982) Resena ecologica de los bosques mediterraneos de Chile. Bosque, 4, 117-146.

[33] Clapp, R.A. (2001) Tree Farming and Forest Conservation in Chile: Do Replacement Forests Leave Any Originals Behind? Society and Natural Resources, 14, 341-356. http://dx.doi.org/10.1080/08941920119176

[34] Warwick, R.M. and Clarke, K.R. (1995) New Biodiversity Measures Reveal a Decrease in Taxonomic Distinctness with Increasing Stress. Marine Ecology Progress Series, 129, 301-305. http://dx.doi.org/10.3354/meps129301

[35] Clarke, K.R. and Warwick, R.M. (1998) A Taxonomic Distinctness Index and Its Statistical Properties. Journal of Applied Ecology, 35, 523-531. http://dx.doi.org/10.1046/j.1365-2664.1998.3540523.x

[36] Clarke, K.R. and Warwick, R.M. (1999) The Taxonomic Distinctness Measure of Biodiversity: Weighting of Step Lengths between Hierarchical Levels. Marine Ecology Progress Series, 184, 21-29. http://dx.doi.org/10.3354/meps184021

[37] Van der Spoel, S. (1994) A Biosystematic Basis for Pelagic Biodiversity. Contributionsto Zoology, 64, 3-31.

[38] Rogers, S., Clarke, K. and Reynolds, J. (2001) The Taxonomic Distinctness of Coastal Bottom-Dwelling Fish Communities of the North-East Atlantic. Journal of Animal Ecology, 68, 769-782.

[39] Väre, H., Lampinen, R., Humphries, C., Williams, P., Nagy, L., Grabherr, G., Körner, C. and Thompson, D. (2003) Taxonomic Diversity of Vascular Plants in the European Alpine Areas. Springer, Berlin.

[40] Ojeda, F., Maranon, T. and Arroyo, J. (2009) Patterns of Ecological, Chorological and Taxonomic Diversity at Both Sides of the Strait of Gibraltar. Journal of Vegetation Science, 7, 63-72. http://dx.doi.org/10.2307/3236417

[41] Simpson, E. (1949) Measurement of Diversity. Nature, 163, 11-13. http://dx.doi.org/10.1038/163688a0

[42] Pielou, E. (1975) Ecological Diversity. Wiley, New York.

[43] Braun Blanquet, J. (1928) Pflanzensoziologie. Grundzüge der Vegetationskunde. Springer, Wien.

[44] Pellissier, V., Gallet, S. and Roze, F. (2004) Comparison of the Vegetation and Seed Bank on Hedge Banks of Different Ages in Brittany, France. Environmental Management, 34, 52-61. http://dx.doi.org/10.1007/s00267-004-0041-x

[45] Armesto, J., Rozzi, R., Smith Ramirez, C. and Arroyo, M. (1998) Conservation Targets in South American Temperate Forests. Science, 282, 1271-1272. http://dx.doi.org/10.1126/science.282.5392.1271

[46] Asmüssen, M. and Simonetti, J. (2007) Can a Developing Country like Chile Invest in Biodiversity Conservation? Environmental Conservation, 34, 183-185. http://dx.doi.org/10.1017/S0376892907004183

[47] Clarke, K. and Warwick, R. (2001) A Further Biodiversity Index Applicable to Species Lists: Variation in Taxonomic Distinctness. Marine Ecology Progress Series, 216, 265-278. http://dx.doi.org/10.3354/meps216265

[48] Price, A., Keeling, M. and O’Callaghan, C. (1999) Ocean-Scale Patterns of Biodiversity of Atlantic Asteroids Determined from Taxonomic Distinctness and Other Measures. Biological Journal of the Linnean Society, 66, 187-203. 